Polymer Degradation and Stability

March 2017, Volume 137, Pages 272-280

http://dx.doi.org/10.1016/i.polymdegradstab.2017.02.003

http://archimer.ifremer.fr/doc/00371/48208/

(c) 2017 Elsevier Ltd. All rights reserved.

\title{
Yield stress changes induced by water in polyamide 6: Characterization and modeling
}

\author{
Le Gac Pierre-Yves ${ }^{1,{ }^{*}}$, Arhant Mael ${ }^{1}$, Le Gall Maelenn ${ }^{1}$, Davies Peter ${ }^{1}$ \\ ${ }^{1}$ IFREMER, Marine Structures Laboratory, Centre de Bretagne, F-29280, France \\ * Corresponding author, Pierre-Yves Le Gac, email address : pierre.yves.le.gac@ifremer.fr
}

\begin{abstract}
:
This paper considers the effect of water content on mechanical properties of polyamide 6 when used in a humid environment. First an experimental section presents the tensile behavior of polyamide with different amounts of water, with and without a through-thickness water gradient. Water profiles are introduced by immersion in sea water at $25^{\circ} \mathrm{C}$. The effect of testing temperature is also investigated in order to consider the influence of macromolecular chain mobility on the mechanical behavior. Then, in a second section, modelling of yield stress is proposed based on physical considerations. This can be used for life time prediction of PA6 in humid environment when plasticization is the main degradation mechanism.
\end{abstract}

Keywords : Yield stress, Water, Polyamide, Plasticization, Prediction 


\section{Introduction}

Polyamides are widely used due to their intrinsic properties such as processability, reparability, and low cost [1-3]. Despite this extensive use, polyamide 6 (PA6) undergoes different types of degradation that lead to large modifications of its mechanical properties during service. For example, PA can become brittle due to oxidation [4, 5]. Considering now humid environment, two main types of degradation can occur; first, plasticization of the polymer occurs due to water diffusion from the external environment into the polymer. This physical degradation induces a large decrease in mechanical properties such as stress at yield or modulus [6-8]. The second mechanism is the hydrolysis of the molecular backbone in PA. This chemical degradation leads to chain scission in the polymer and also results in significant changes in mechanical properties [9-11], but this degradation mechanism will not be considered in this paper. In fact, ageing times are short enough to avoid any hydrolysis of the polymer, in order to focus only on plasticization [9-10].

The presence of water in PA6 leads to a large modification of mechanical properties induced by an increase in the mobility of macromolecular chains. This increase in mobility leads to a decrease in both Young's modulus and yield stress, whereas elongation at break is increased. For example, Silva et al. found a decrease of $80 \%$ in modulus when PA6 was saturated with water at $20^{\circ} \mathrm{C}$. Despite this large change in mechanical properties induced by the presence of water, the use of polyamide 6 in a marine environment is still attractive, provided that we are able to predict the long term decrease in yield strength. This is especially important when structures are thick, with heterogeneous water content through their thickness.

In a previous paper [12] a new model to describe water absorption was proposed. It was shown that water absorption in PA6 cannot be described by a simple Fickian behavior due to changes in water diffusivity with water activity when the polymer goes from the glassy to the rubbery state; this behavior is known as case II diffusion [13]. The proposed model involves a step by step process; first the local water content in the polymer is described. Then, an evaluation of the local $\mathrm{T}_{\mathrm{g}}$ is made based on the Sihma-Boyer equation [14, 15]. And, finally the local diffusivity of water is calculated as follows: When the polymer is in the glassy state, water diffusion depends only on temperature and can be described using an Arrhenius expression [16]. Whereas when the polymer is in the rubbery state water diffusion depends on 


\section{ACCEPTED MANUSCRIPT}

both temperature and water activity, in this case diffusivity is successfully described by the free volume theory [17-20]. The proposed model has been validated using comparison with water absorption measurements on $2 \mathrm{~mm}$ thick samples immersed in sea water at temperatures from 15 to $60^{\circ} \mathrm{C}$. This model was the first step towards prediction of properties when PA6 samples are immersed in sea water. The present paper is the second step, and consists of characterizing, understanding and describing the relationship between water content and mechanical properties.

This paper will describe the changes in mechanical performance induced by immersion in sea water. First, experimental results will be presented with special attention paid to changes in tensile behavior induced by mobility in the PA6. Then, these results will be discussed and a relationship between water content and yield stress will be proposed based on physical considerations. Finally, using this relationship coupled with the diffusion model, a prediction of property changes will be made. This prediction will be validated by comparison with other experimental data. 


\section{Material and methods}

\section{$\underline{\text { Material }}$}

The polymer used in this study is a commercial Polyamide 6 in the form of $2 \mathrm{~mm}$ thick sheet supplied as the reference AM303020 by Goodfellow. The main characteristics are reported in Table 1. All samples tested here were cut using a high-pressure water jet machine, then dried at $40^{\circ} \mathrm{C}$ in a desiccator until a constant mass was reached. The sheet is processed by compression molding so the polymer is considered to be isotropic.

\begin{tabular}{|c|c|}
\hline Properties & Values \\
\hline Density & $1130 \mathrm{~kg} \cdot \mathrm{m}^{-3}$ \\
\hline $\mathrm{T}_{\mathrm{g}}$ (Dry) & $66^{\circ} \mathrm{C}$ \\
\hline Crystallinity & $38 \%$ \\
\hline $\mathrm{M}_{\mathrm{n}}$ & $48 \mathrm{~kg} \cdot \mathrm{mol}^{-1}$ \\
\hline Modulus (Dry) & $2.3 \mathrm{GPa}$ \\
\hline
\end{tabular}

Table 1: Main physical characteristics of the PA 6 studied here

\section{$\underline{\text { Method }}$}

Ageing

Two kinds of ageing were considered here. The first one is immersion in natural and renewed sea water that comes directly from the Brest estuary. In this case the temperature is $25 \pm 1{ }^{\circ} \mathrm{C}$. Samples were tested directly after removal from the ageing tank in order to limit water evaporation. The second one aims to obtain samples at different water contents with no water profile through thickness. To do so, samples are conditioned for $48 \mathrm{~h}$ at $80^{\circ} \mathrm{C}$ at several humidity levels (see Table 2) using a Servathin conditioning chamber. The water content in the polymer was determined based on the weight gain of samples after exposure. For each conditions, 3 samples were tested. Samples fully saturated in sea water were dried at $25 \pm 1^{\circ} \mathrm{C}$ in a desiccator maintained at $0 \% \mathrm{RH}$. The tensile samples were dried at $80^{\circ} \mathrm{C}$ for $48 \mathrm{~h}$ in order to reduce drying time. The water content in samples was determined by weight measurements.

\section{Size Exclusion chromatography (SEC)}

Molar mass was determined by SEC made by PeakExpert Compagny according to Laun and al. method [21] and used in [4]. Samples of 25mg were dissolved in 10ml of 1,1,1,3,3,3hexafluoroisopropan-2-ol (HFiP) the dissolution was performed for $24 \mathrm{~h}$ at room temperature. 
Samples were injected in the chromatograph (Waters 2695) after a filtration on PTFE $0.2 \mu \mathrm{m}$. The separation was performed using a pre-column and two columns packed with 7- $\mu \mathrm{m}$ PFG particles, and $1000 \AA$ and $100 \AA$ pore size, the dimension of columns was $8 \mathrm{~mm} \mathrm{ID} \times 300 \mathrm{~mm}$ length. The mobile phase was a mixture of $\mathrm{HFiP}+0.05 \mathrm{~mol} 1-1$ potassium trifluoroacetate (KTFAc), flow rate was $1 \mathrm{ml} \mathrm{min}{ }^{-1}$ and injection volume was $50 \mu l$. The detection module was performed using a Waters 2414 differential refractive index detector and data treated with PSS WinGPC unity v7.5 SEC software. The calibration was built using poly(methyl methacrylate) standards supplied by PSS GmbH Mainz, Germany, with molar mass ranging between 800 and $1600000 \mathrm{~g}$ mol-1 and calibration curve was adjusted with an order 5 polynomial. Calculations are conventional and average molecular weights are expressed in PMMA equivalent.

\section{Tensile Tests}

Tensile tests were performed using a $10 \mathrm{kN}$ capacity Instron machine with a load cell of 10 $\mathrm{kN}$. Samples were tested under displacement control at a rate of $6 \mathrm{~mm} /$ minute. The strain was measured by digital image correlation based on the displacement of two marker points on the specimen, using in-house software. For tests at different temperatures, samples were conditioned prior to testing in a desiccator at $0 \% \mathrm{RH}$ at the same temperature as the tensile test for at least 48 hours, to ensure homogeneous temperature and no water in the samples. From tensile plots both modulus and yield stress were determined; the modulus was calculated with the slope from 0 to $1 \%$ strain, the yield stress was defined as the stress where the stress-strain plot deviates by $5 \%$ from linear behaviour. This is an arbitrary criterion, but one which is used in several standard test methods, being easy to apply and corresponding to a significant deviation from linearity. For each condition, 3 samples were tested.

\section{DMA measurements}

Dynamic Mechanical Analysis (DMA) was performed in tensile mode on rectangular samples (30 mm long, $15 \mathrm{~mm}$ wide and $2 \mathrm{~mm}$ thick). The dynamic strain was equal to $2.10^{-4}$ and the static strain was $8.10^{-4}$. Temperature was raised from $-50^{\circ} \mathrm{C}$ to $100^{\circ} \mathrm{C}$ at a rate of $2^{\circ} \mathrm{C} / \mathrm{min}$ and the $T_{g}$ was determined as the temperature corresponding to the maximum of the tangent delta. This kind of measurement is not easy because of water evaporation during the test. Here, thanks to the sample thickness, time for evaporation is much longer than testing time so this effect can be neglected. 3 samples were tested per condition.

\section{Modeling}


Modeling was performed using commercial software, Comsol Multiphysics 5.1. A 2D model was used with a quadratic mesh with a minimum of 100 elements on each edge. Due to sample symmetry only $1 / 4$ of the sample was modelled and symmetry conditions were applied to two boundaries. On the two other boundaries a water activity of 0.98 , corresponding to liquid water [22-24] was applied. Both modulus and stress at yield were obtained using an integration of local values.

\section{Results}

This section will present the experimental results of the study.

\section{Water content}

In order to investigate water effect on mechanical properties, two distinct cases are considered here. First, when the polymer is at saturation i.e. the water concentration is homogenous throughout the sample thickness, and second, before saturation, i.e. when there is a gradient of water concentration through the sample thickness.

\section{$\underline{\text { Homogenous water content }}$}

A homogeneous water content in the sample thickness is achieved when the saturation is reached. In order to vary the water content in the polymer, samples were conditioned at several humidity levels, leading to different water contents. Values are reported in Table 2.

\begin{tabular}{|c|c|}
\hline Environmental conditions & Homogeneous water content (\%) \\
\hline $80^{\circ} \mathrm{C}, 20 \% \mathrm{RH}, 48$ hours & 0.7 \\
\hline $80^{\circ} \mathrm{C}, 30 \% \mathrm{RH}, 48$ hours & 1.1 \\
\hline $80^{\circ} \mathrm{C}, 40 \% \mathrm{RH}, 48$ hours & 1.7 \\
\hline $80^{\circ} \mathrm{C}, 50 \% \mathrm{RH}, 48$ hours & 2.4 \\
\hline $80^{\circ} \mathrm{C}$, sea water, 48 hours & 9.3 \\
\hline
\end{tabular}

\section{Table 2: Water content in the PA6 as a function of conditioning parameters}

These samples with a homogenous water content are useful to set up the relationship between the water content and mechanical properties (see below).

\section{$\underline{\text { Heterogeneous water content }}$}

In order to be able to model the loss in yield stress when PA6 is immersed in sea water it is necessary to take into account the water profile in samples and thus to consider diffusion kinetics. Figure 1 shows the water absorption in $2 \mathrm{~mm}$ thick PA6 when immersed in natural 
sea water at $25^{\circ} \mathrm{C}$. The continuous line is the model prediction for water absorption proposed in [12] and that will be used here for the prediction. In order to validate this prediction, the drying process has also been considered. Figure $1 \mathrm{~b}$ shows the water desorption in the same sample at $25^{\circ} \mathrm{C}$ and $0 \% \mathrm{RH}$, following saturation. It is worth noting that the desorption rate is much slower than the absorption, this is a strong confirmation of the non Fickian water absorption in PA6.
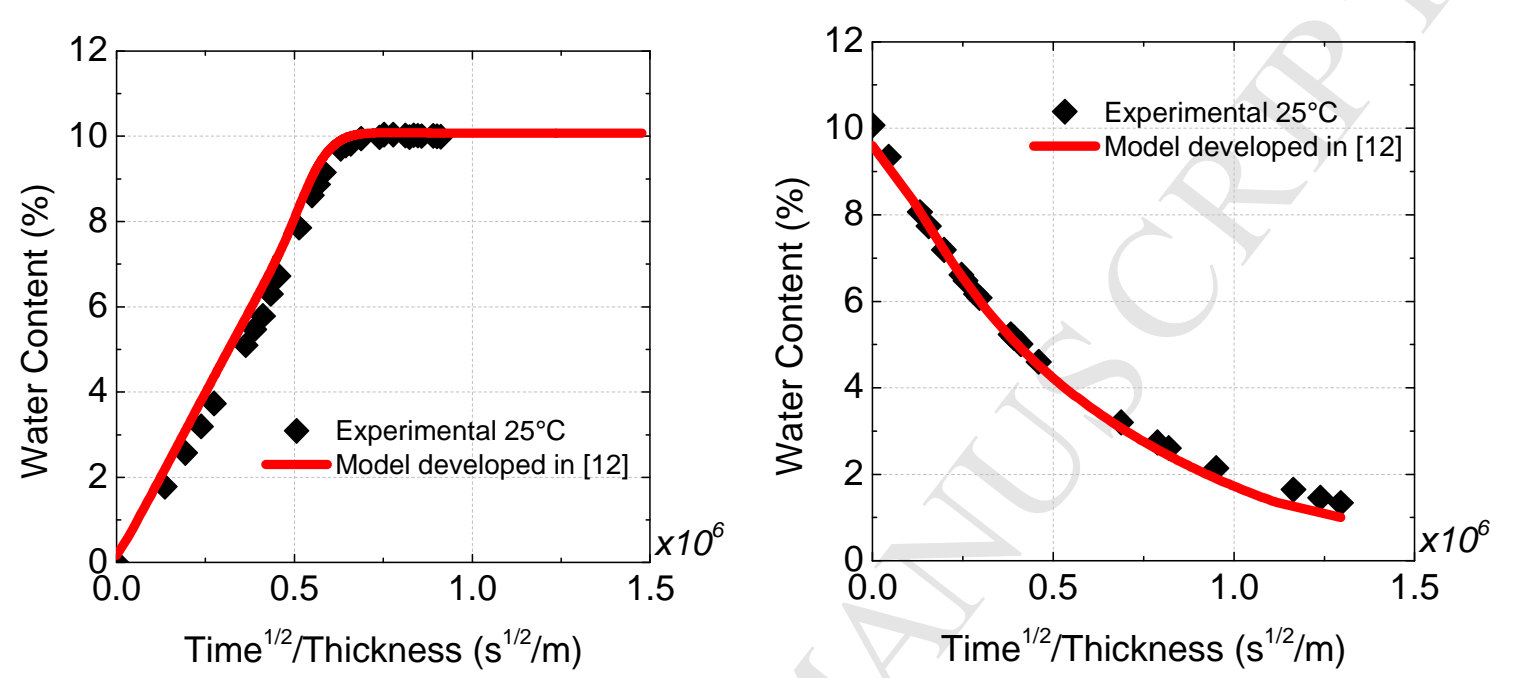

Figure 1: Water absorption when immersed in sea water (left) and desorption at $0 \% \mathrm{RH}$ (right) in $2 \mathrm{~mm}$ thick PA6 samples (dots are experimental data and lines show the model developed in [12]).

SEC

In order to confirm that hydrolysis is not involved during ageing in the conditions considered here, SEC measurement have been performed in three conditions: prior ageing, after ageing in sea water for 6 months with and without drying. Results are presented in Table 3.

\begin{tabular}{|l|c|c|c|}
\hline Sample type & Mn (kg/mol) & Mw (kg/mol) & IP \\
\hline Unaged & 48 & 121 & 2.5 \\
\hline Aged 6 months at $25^{\circ} \mathrm{C}$ in sea water & 50 & 117 & 2.3 \\
\hline Aged 6 months at $25^{\circ} \mathrm{C}$ in sea water and then dried & 49 & 115 & 2.3 \\
\hline
\end{tabular}

Table 3: SEC results obtained before and after ageing with and without drying

There is no change in the molecular weight and distribution in the polymer during ageing and drying after ageing, in the condition considered in this study, i.e. sea water at $25^{\circ} \mathrm{C}$ for a 
maximal duration of 6 months. This is a clear validation of the fact that hydrolysis is not involved here.

\section{Tensile tests}

Changes in tensile behavior of polyamide 6 corresponding to changes in macromolecular chain mobility are described here. First, the effect of water content with no gradient is considered. Then, testing temperature effects on dried samples will be shown. Finally, tensile curves for samples with water profiles through thickness will be presented.

\section{$\underline{\text { Tensile test with different water contents with no profile }}$}

Figure 2 shows examples of the tensile curves of PA6 for different amounts of water. For the dried samples (i.e when there is no water in the polymer), we observe a typical ductile behavior for a semi-crystalline polymer in the glassy state. An initial linear elastic region is observed first, followed by a yield stress after which strain softening ('yield drop') occurs, and finally a break in the plastic region.

The presence of water in the amorphous phase of the PA6 leads to an increase of the mobility of macromolecular chains that induces a large decrease in both Young's modulus and stress at yield. It is worth noting that there is no water gradient through the sample thickness here, the water content in the polymer is controlled using exposures at several humidity levels but the exposure time is long enough to result in an homogeneous distribution of water in the sample thickness.

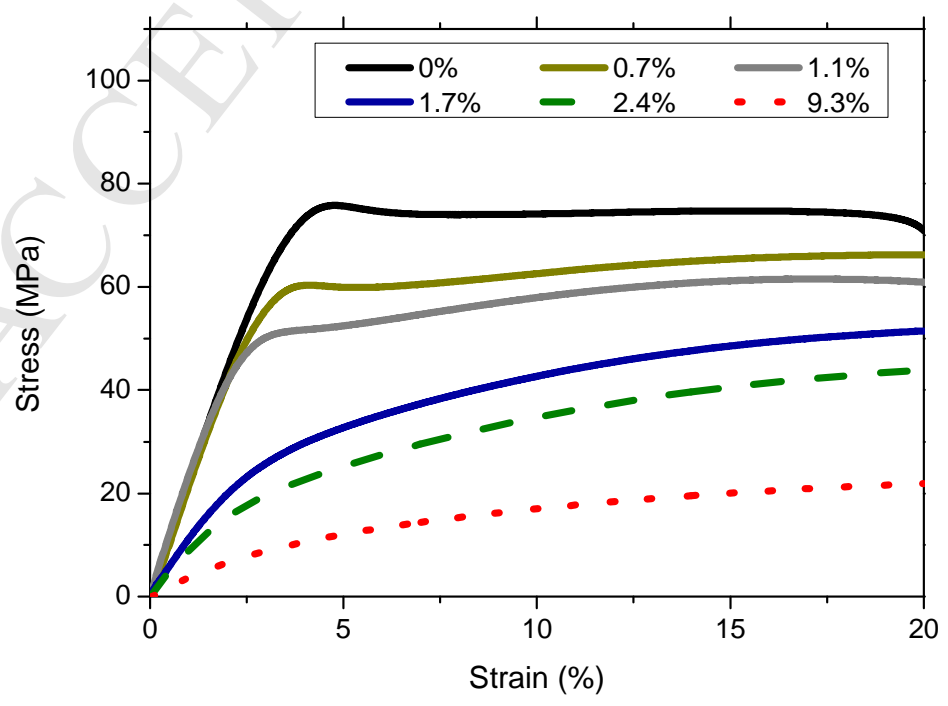

Figure 2: Tensile curve of PA6 as function of water content with no profile 
Figure 3 shows that the tensile modulus decreases from 2.3 to $0.4 \mathrm{GPa}$ when water absorption increases to about $9 \%$. At the same time, the yield stress is reduced by more than $90 \%$. This large effect of water on mechanical properties of PA6 has already been described in the literature [6] and is attributed to an increase in chain mobility in the presence of water. The effect of mobility induced by raising testing temperature is considered in the next section.
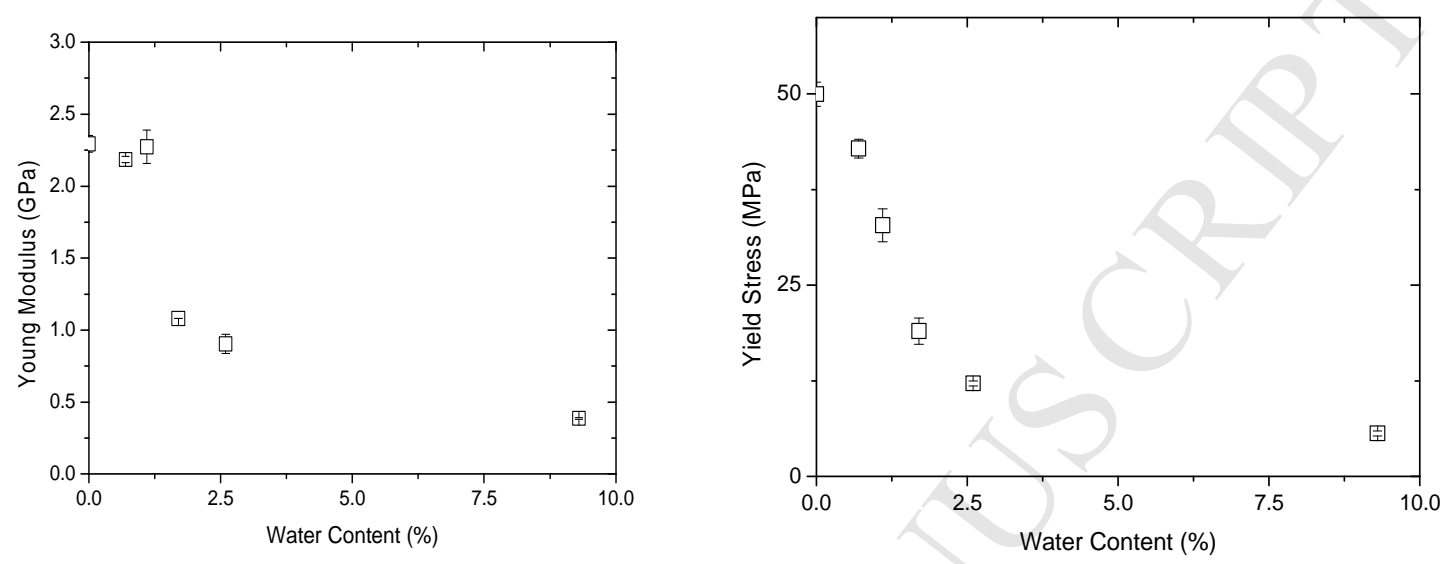

Figure 3: Young's modulus (left) and Yield stress (right) as a function of water content in PA 6 with no water gradient.

\section{Temperature effect on tensile behavior}

This section aims to quantify the effect of mobility induced by raising test temperature on the tensile behavior of the polymer. Dried PA6 samples were tested at several temperatures ranging from $4^{\circ} \mathrm{C}$ (the deep ocean water temperature) up to $80^{\circ} \mathrm{C}$ (above the $\mathrm{T}_{\mathrm{g}}$ ), examples of results are shown in Figure 4.

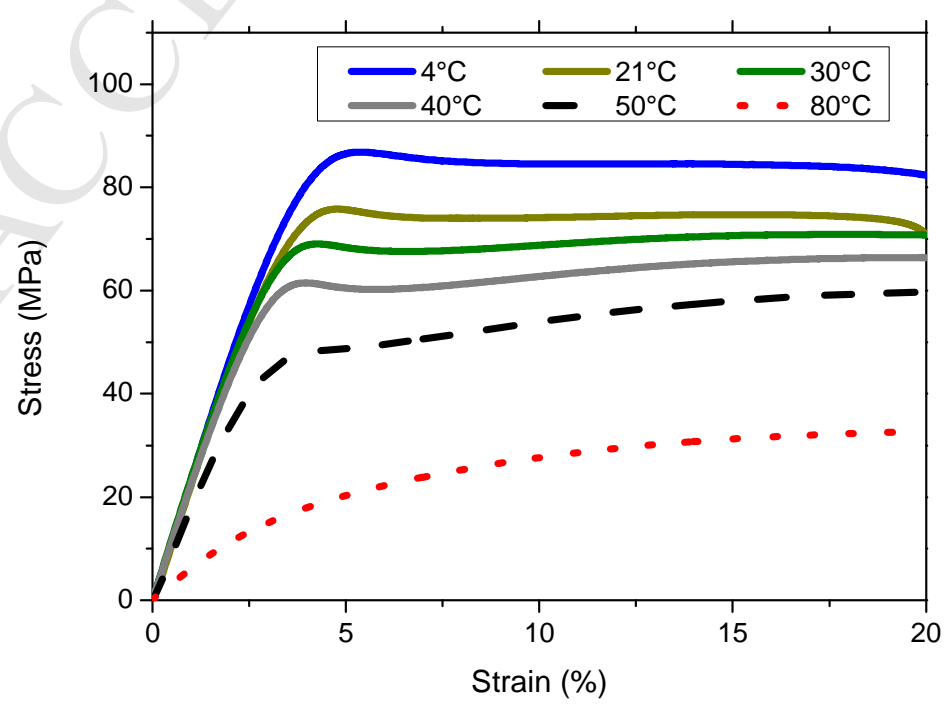




\section{Figure 4: Effect of testing temperature on tensile behavior of PA6}

As expected, the increase in temperature leads to a large decrease in both the modulus and the stress at yield. This decrease is well documented in the literature [25, 26] and attributed to an increase in molecular mobility (Figure 5). These data will be used to set up a relationship between the increase in mobility and mechanical behavior of the PA6 (see below).
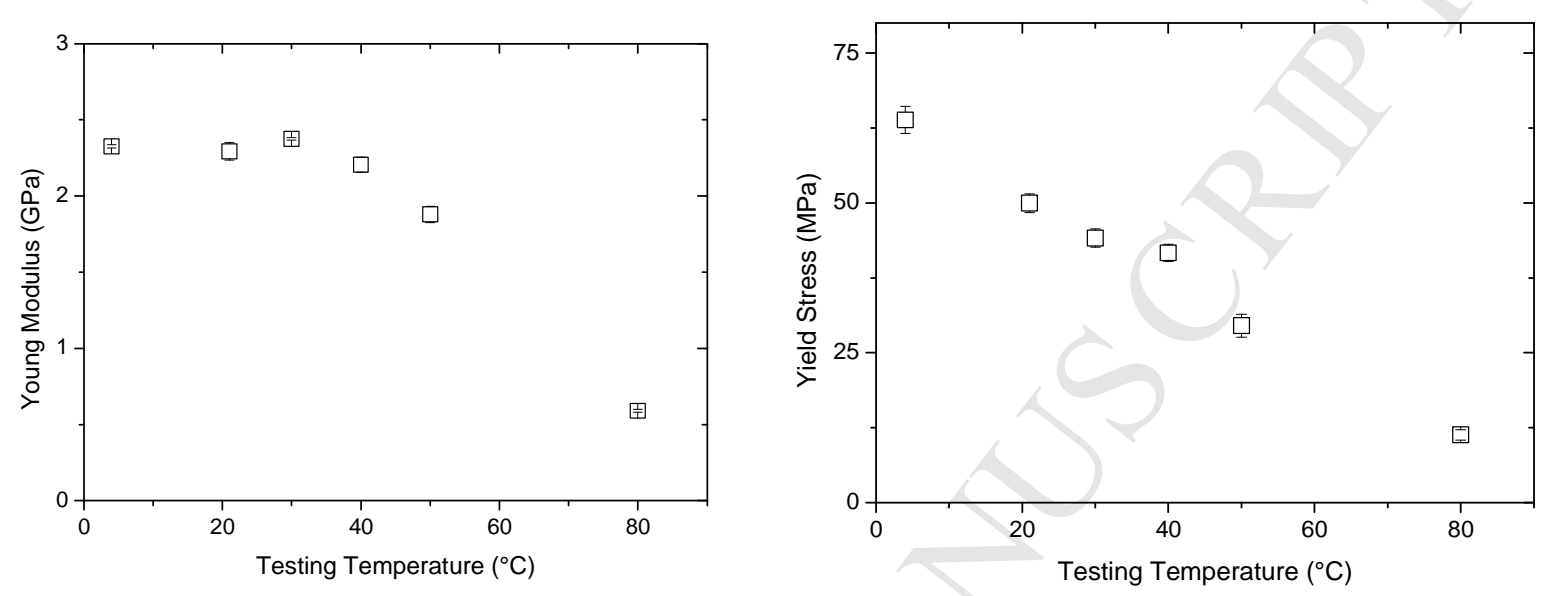

Figure 5: Young's modulus (on the left) and Yield stress (on the right) as a function of testing temperature

\section{$\underline{\text { Tensile test after immersion in sea water for several durations }}$}

Samples were immersed in natural sea water at $25^{\circ} \mathrm{C}$ and removed after several durations. Because testing is performed before water saturation a water profile exists through the sample thickness. Examples of results are plotted in Figure 6. These data will be used in the next section to compare with values obtained from the model.

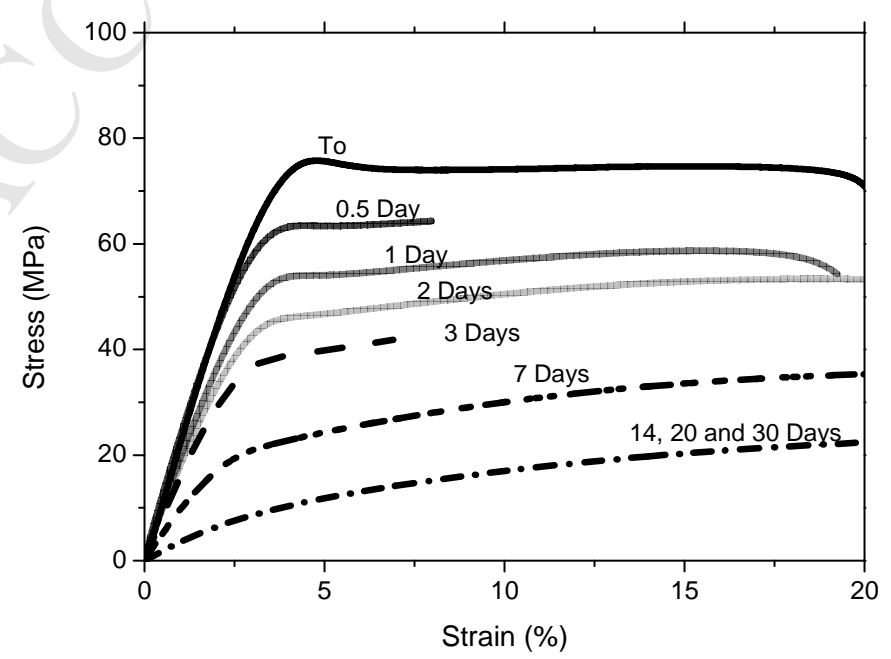


Figure 6: Tensile curves for $2 \mathrm{~mm}$ thick PA6 after different immersion times in sea water at $25^{\circ} \mathrm{C}$
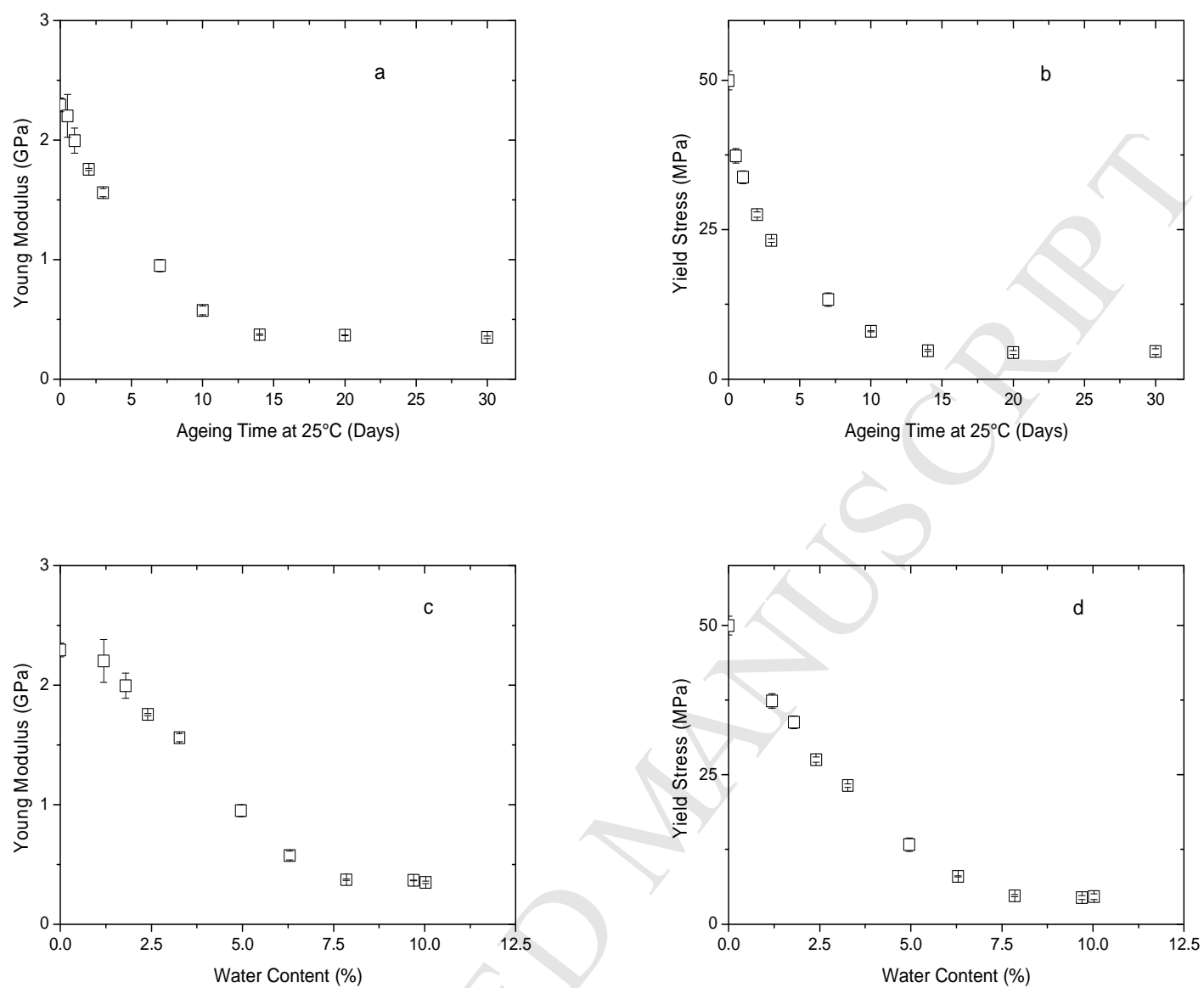

Figure 7: Young's modulus and Yield stress during water sorption as a function of immersion time in sea water at $25^{\circ} \mathrm{C}$ (a \&b) and as function of water content (c \& d)

A clear drop in both modulus and yield stress is observed during immersion in sea water (Figure 7). This is caused by a plasticization mechanism and will be discussed in more detail later. It is worth noting that both the amount of absorbed water and the consequences on mechanical properties are coherent between immersion and ageing in humid conditions (Figure 5).

\section{Tensile tests after immersion in sea water during water desorption}

During the drying process, the water profile through the sample thickness is not the same as for water absorption due to different boundary conditions. Here samples were first fully saturated in sea water at $25^{\circ} \mathrm{C}$ for a month and then dried at the same temperature for different durations. Examples of results are presented in Figure 8. It should be noted that the sample 
dried for 78 days at $25^{\circ} \mathrm{C}$ has then been placed at $80^{\circ} \mathrm{C}$ and $0 \% \mathrm{RH}$ to accelerate the drying process for 24 hours, the final water content was $0.3 \%$.

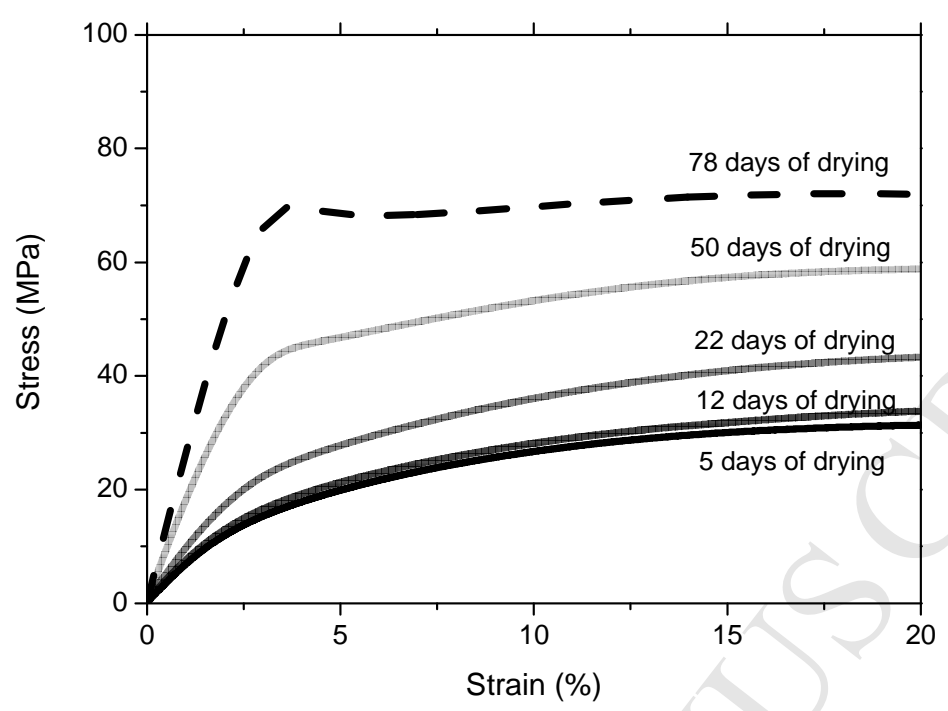

Figure 8: Tensile curves of $2 \mathrm{~mm}$ thick PA6 after different drying times following complete saturation in sea water at $25^{\circ} \mathrm{C}$.
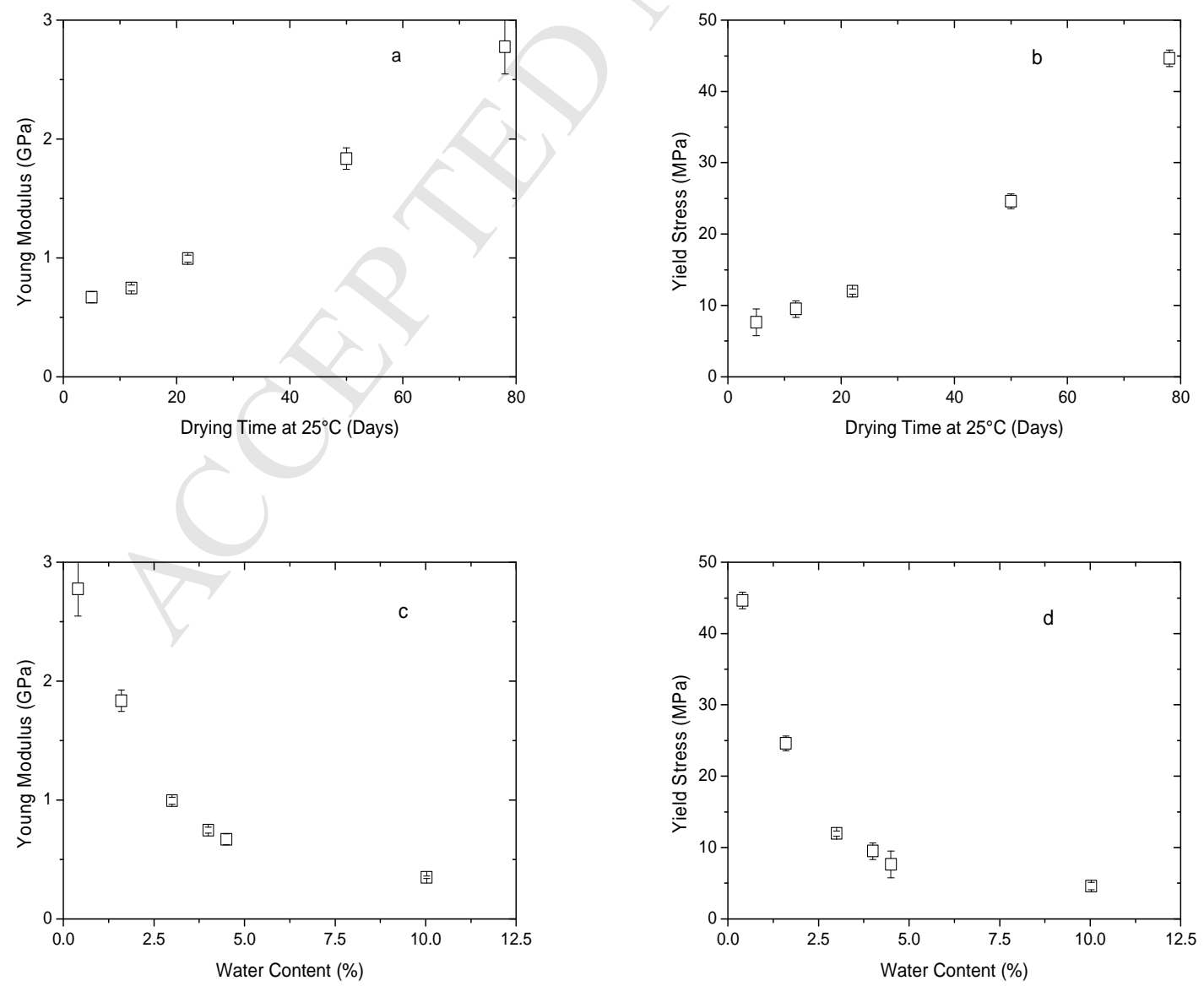
Figure 9: Young's modulus and Yield stress during water desorption as a function of drying time at $25^{\circ} \mathrm{C}(\mathrm{a} \& \mathrm{~b})$ and as function of water content (c \& d)

During the drying process, water is removed from the polymer leading to an increase of both modulus and stress at yield (Figure 9). Properties of the sample with only $0.3 \%$ of water are close to those of the unaged samples, highlighting the fact that plasticization is a reversible mechanism.It is worth noting that the time to recover mechanical properties is much longer than the time to reduce these properties, this is in accordance with water absorption and desorption rates (Figure 1).

\section{DMA Results}

It is well known that the presence of water within polymers leads to an increase in macromolecular chain mobility and to a decrease in the glass transition temperature. Here DMA was used to measure this change in $T_{g}$ with water content, as shown in Figure 10. In PA6, the $\mathrm{T}_{\mathrm{g}}$ decreases from $66^{\circ} \mathrm{C}$ in the dry state to about $-10^{\circ} \mathrm{C}$ when saturated with water, meaning that when the polymer is used at $20^{\circ} \mathrm{C}$ in water after a certain time it will switch from the glassy state to the rubbery state.

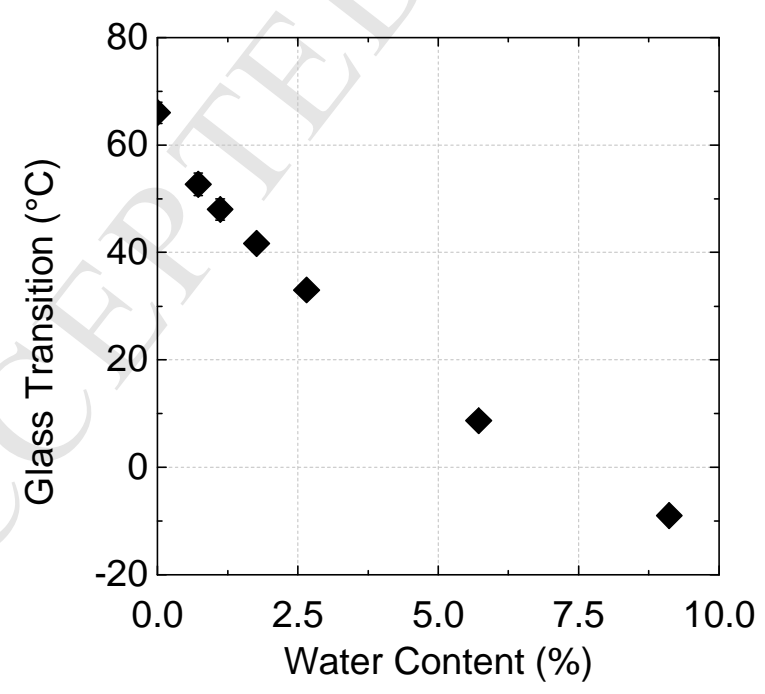

Figure 10: Changes in $T_{g}$ with water content measured by DMA (error bars are within the symbols) 


\section{4 - Interpretation and modeling}

This section is devoted to the interpretation of the data presented previously, in order to set up a relationship between the stress at yield and the macromolecular chain mobility in PA6. This change in chain mobility can be induced either by raising temperature or by the presence of water as noted in the introduction.

To set up such a prediction, it is first necessary to be able to predict local water content in a thick PA6 sample, then to have a reliable relationship between the water content and the stress at yield, to integrate this in a mechanical model, and finally to evaluate the accuracy of the prediction by comparing other experimental results to predictions. Relationship between water content and stress at yield

It is well known that stress at yield is related to the chain mobility that can be characterized through the $T_{g}$ value [27]. As the water content increases in PA6, the chain mobility increases and so the $T_{g}$ decreases (Figure 10), this decrease in $T_{g}$ leads to a stress at yield drop (Figure $3 b$ ). When chain mobility is increased by raising the testing temperature (Figure $5 b$ ), the same result is observed: a large drop in yield stress. This behavior can be described using the following relationship [28], Figure 11:

$$
\sigma_{y}=A *\left(T_{g}-T\right)+B
$$

Where $\sigma_{\mathrm{y}}$ is the yield stress, $\mathrm{T}_{\mathrm{g}}$ the glass transition temperature, $\mathrm{T}$ the testing temperature and $\mathrm{A}$ and $\mathrm{B}$ experimental factors that depend on the polymer.

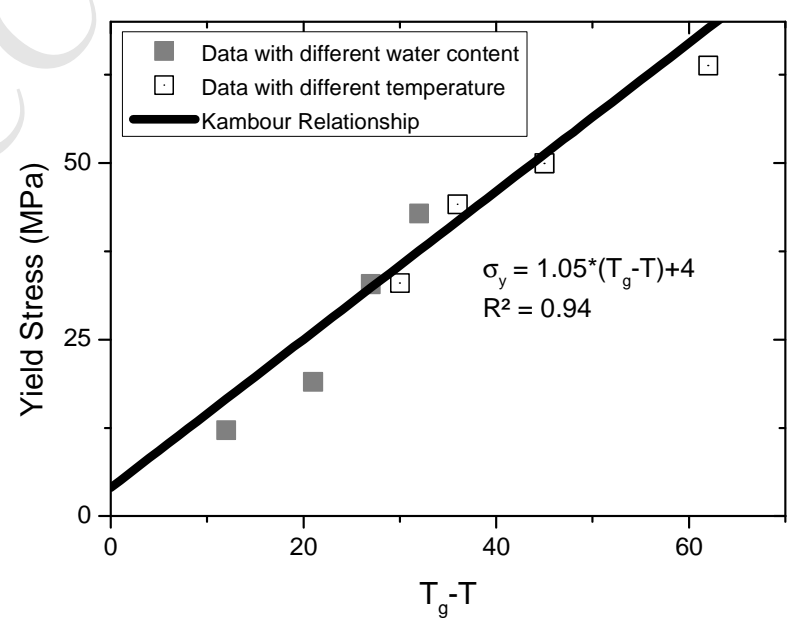




\section{Figure11: Stress at yield as function of $\mathbf{T}_{\mathrm{g}}$}

Such relationships were suggested by the studies of Kambour, who simplified the Eyring equation by considering a constant strain rate. This equation has been used for polymers such as epoxies [29]. Here, for PA6, the proportionality constant $\mathrm{A}$ is found to be equal to 1.05 $\mathrm{MPa} / \mathrm{K}$. Moreover it appears in Figure 11 that the Kambour equation is verified in glassy state whatever the origin of the mobility change (water content or testing temperature), this fact underlines the universality of this behavior.

It has to be noted that we only considered the polymer in the glassy state, in fact when the testing temperature is above $\mathrm{T}_{\mathrm{g}}$ (i.e. the amorphous phase is in the rubbery state) there is no longer a clear yield point.

\section{Comparison between prediction and experimental data}

Based on results described previously, it is now possible to predict the local water content through the thickness when PA6 is immersed in sea water, and knowing this local water content we can evaluate the local value of $\mathrm{T}_{\mathrm{g}}$. An example for $2 \mathrm{~mm}$ thick PA6 immersed in sea water at $25^{\circ} \mathrm{C}$ is plotted in Figure 12. The unusual profiles observed are induced by the large increase in diffusivity when the polymer goes from the glassy to the rubbery state. Knowing the local $\mathrm{T}_{\mathrm{g}}$ value and using the Kambour relationship a prediction of changes in stress at yield can be made by integrating values through the 100 elements used in the model; results are shown in Figure 13.
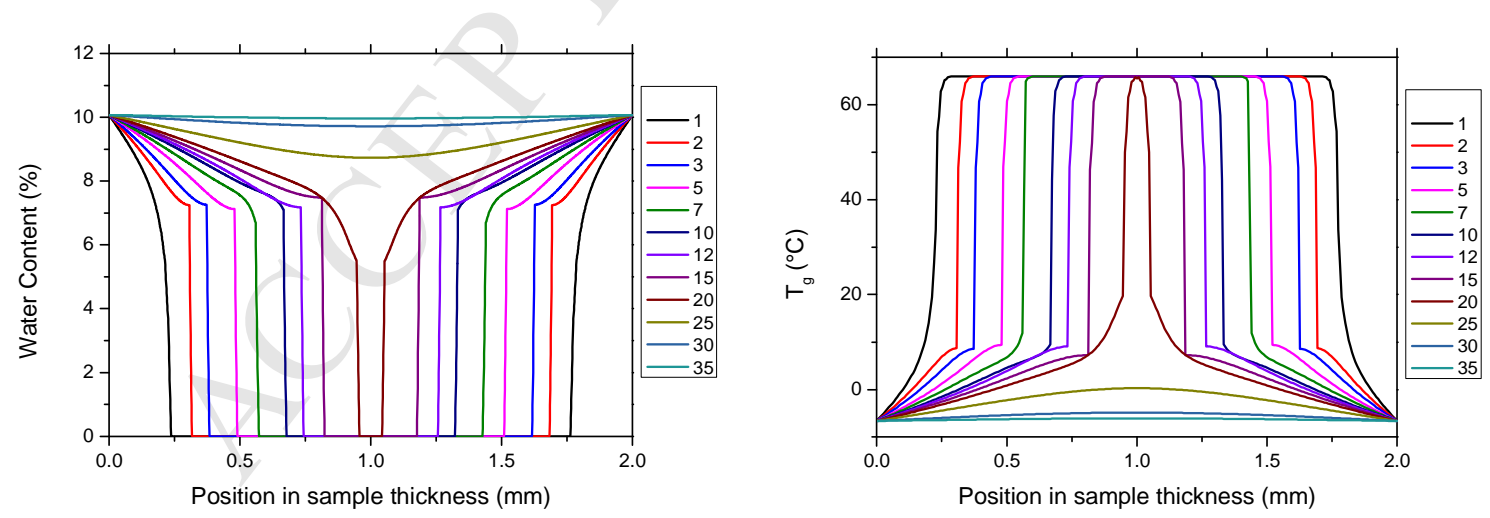

Figure 12: Water profile through sample thickness (left) and change in $T_{g}$ (right) as a function of immersion time (in days) in natural sea water at $25^{\circ} \mathrm{C}$ 


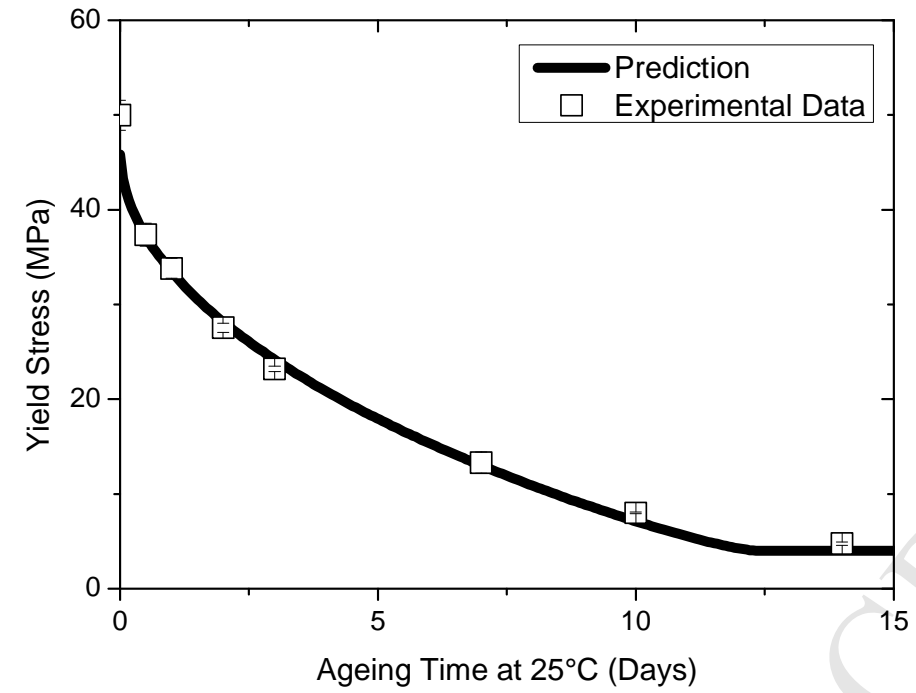

Figure 13: Comparison between experimental stress at yield and predicted values when PA6 is immersed in sea water at $25^{\circ} \mathrm{C}$

It appears that the proposed prediction of the decrease in stress at yield induced by water diffusion is in good agreement with experimental data, so this prediction can now be used to investigate the behavior of thicker PA6 parts used in sea water for long periods. 


\section{Conclusions}

The presence of water in polyamide 6 leads to an increase of macromolecular chain mobility that significantly changes the mechanical behavior of the polymer. This paper proposes a new prediction of yield stress decrease during immersion in sea water.

In order to develop a reliable model, a relationship between water content and stress at yield is necessary. This relationship has been developed based on experimental data, tensile tests have been conducted on dry samples at several temperatures and on samples with different water contents (but no gradients). Results clearly show that the stress at yield is directly related to the difference between the $T_{\mathrm{g}}$ and testing temperature and can be described by the Kambour's relationship in the glassy state. It has to be noted, that the model proposed here does not consider strain rate effects, these could be added to the model in the future.

Using this relationship between yield stress and water content together with a specific diffusion model described elsewhere, a prediction of the decrease in stress at yield induced by plasticization during immersion in sea water has been developed for the first time. This prediction has been validated by comparison with experimental data during both water absorption and drying.

When polyamides are used in sea water, hydrolysis of the polymer can also occur, and this will also affect mechanical properties. This chemical degradation is not included yet, work is underway to add this irreversible degradation to the model.

\section{Acknowledgments}

The authors wish to thank N. Lacotte and M. Premel-Cabic of Ifremer for their expertise with ageing tests. 


\section{References}

[1] Mourglia-Seignobos, E., Long, D. R., Odoni, L., Vanel, L., Sotta, P., \&Rochas, C. (2014). Physical mechanisms of fatigue in neat polyamide 6, 6. Macromolecules, 47(12), 3880-3894.

[2] Launay, A., Marco, Y., Maitournam, M. H., Raoult, I., \&Szmytka, F. (2010). Cyclic behavior of short glass fiber reinforced polyamide for fatigue life prediction of automotive components. Procedia Engineering, 2(1), 901-910.

[3] Arhant, M., Le Gac, P. Y., Le Gall, M., Burtin, C., Briançon, C., \& Davies, P. (2016). Effect of sea water and humidity on the tensile and compressive properties of carbonpolyamide 6 laminates. Composites Part A: Applied Science and Manufacturing, 91, 250-261. [4] Okamba-Diogo O, Richaud E, Verdu J, Fernagut F, Guilment J, Fayolle B. Molecular and macromolecular structure changes in polyamide 11 during thermal oxidation. Polym Degrad Stab. 2014 Oct;108:123-32.

[5] Gijsman P, Dong W, Quintana A, Celina M. Influence of temperature and stabilization on oxygen diffusion limited oxidation profiles of polyamide 6. Polym Degrad Stab. 2016 Aug;130:83-96.

[6] Silva L, Tognana S, Salgueiro W. Study of the water absorption and its influence on the Young's modulus in a commercial polyamide. Polym Test. 2013 Feb;32(1):158-64.

[7] Miri, V., Persyn, O., Lefebvre, J. M., \& Seguela, R. (2009). Effect of water absorption on the plastic deformation behavior of nylon 6. European Polymer Journal, 45(3), 757-762.

[8] Reimschuessel HK. Relationships on the effect of water on glass transition temperature and young's modulus of nylon 6. J Polym Sci Polym Chem Ed. 1978 Jun 1;16(6):1229-36.

[9] Bernstein R, Gillen KT. Nylon 6.6 accelerating aging studies: II. Long-term thermaloxidative and hydrolysis results. Polym Degrad Stab. 2010 Sep;95(9):1471-9.

[10] Bernstein R, Derzon DK, Gillen KT. Nylon 6.6 accelerated aging studies: thermaloxidative degradation and its interaction with hydrolysis. Polym Degrad Stab. 2005 Jun;88(3):480-8.

[11] El-Mazry C, Correc O, Colin X. A new kinetic model for predicting polyamide 6-6 hydrolysis and its mechanical embrittlement. Polym Degrad Stab. 2012 Jun;97(6):1049-59.

[12] Arhant, M., Le Gac, P. Y., Le Gall, M., Burtin, C., Briançon, C., \& Davies, P. (2016). Modelling the non Fickian water absorption in polyamide 6. Polymer Degradation and Stability, 133, 404-412.

[13] Crank J. The mathematics of diffusion. 2d ed. Oxford, [Eng]: Clarendon Press; 1975. p. 414

[14] Lim L-T, Britt IJ, Tung MA. Sorption and transport of water vapor in nylon 6,6 film. J Appl Polym Sci. 1999 Jan 10;71(2):197-206.

[15] Broudin M, Le Saux V, Le Gac PY, Champy C, Robert G, Charrier P, et al. Moisture sorption in polyamide 6.6: Experimental investigation and comparison to four physical-based models. Polym Test. 2015 May;43:10-20.

[16] Broudin M, Le Gac PY, Le Saux V, Champy C, Robert G, Charrier P, et al. Water diffusivity in PA66: Experimental characterization and modeling based on free volume theory. Eur Polym J. 2015 Jun;67:326-34.

[17] Kelley FN, Bueche F. Viscosity and glass temperature relations for polymer-diluent systems. J Polym Sci. 1961 Apr 1;50(154):549-56.

[18] Vrentas JS, Duda JL. Diffusion in polymer-solvent systems. I. Reexamination of the free-volume theory. J Polym Sci Polym Phys Ed. 1977;15(3):403-416. 
[19] Vrentas JS, Duda JL. Diffusion in polymer-solvent systems. II. A predictive theory for the dependence of diffusion coefficients on temperature, concentration, and molecular weight. J Polym Sci Polym Phys Ed. 1977;15(3):417-439.

[20] Hong S-U. Prediction of polymer/solvent diffusion behavior using free-volume theory. Ind Eng Chem Res. 1995;34(7):2536-2544.

[21] Laun S, Pasch H, Longieras N, Degoulet C. Molar mass analysis of polyamides-11 and 12 by size exclusion chromatography in hexafluoroisopropanol Polymer. Vol. 49, 21, 2008, p. $4502-4509$

[22] Robinson RA. The vapour pressure and osmotic equivalence of sea water. J Mar Biol Assoc U K. 1954 Jun;33(2):449-455.

[23] Reuvers NJW, Huinink HP, Fischer HR, Adan OCG. The influence of ions on water transport in nylon 6 films. Polymer. 2013 Sep 6;54(20):5419-28.

[24] Le Gac PY, Roux G, Davies P, Fayolle B, Verdu J. Water clustering in polychloroprene. Polymer. 2014 Jun 6;55(12):2861-6.

[25] Reis, J. M. L., de Santanna, T., Coutinho, P. P., Monteiro, A. H., Teixeira, S. C. S., Chaves, E. G., \& da Costa Mattos, H. S. (2016). Coupled effect of ageing and temperature in the mechanical behaviour of a polyamide. Polymer Testing, 53, 267-275.

[26] Wang, L., Dong, X., Huang, M., \& Wang, D. (2016). Transient microstructure in long alkane segment polyamide: Deformation mechanism and its temperature dependence. Polymer, 97, 217-225.

[27] Pascault, J. P., Sautereau, H., Verdu, J., \& Williams, R. J. (2002). Thermosetting polymers (Vol. 64). CRC Press.

[28] Kambour, R. P. (1973). A review of crazing and fracture in thermoplastics. Journal of Polymer Science: Macromolecular Reviews, 7(1), 1-154.

[29] Cook, W. D., Mayr, A. E., \& Edward, G. H. (1998). Yielding behaviour in model epoxy thermosets-II. Temperature dependence. Polymer, 39(16), 3725-3733. 